OPEN ACCESS

Edited by:

Daphne Haas-Kogan,

Brigham and Women's Hospital and Harvard Medical School, United States

Reviewed by:

Christopher Paul Cifarelli, West Virginia University Hospitals, United States

Jung Sun YoO,

Hong Kong Polytechnic University,

Hong Kong

*Correspondence:

Hongmei Liu

liuhongmei816@sina.com

${ }^{\dagger}$ These authors have contributed equally to this work

Specialty section: This article was submitted to

Radiation Oncology,

a section of the journa

Frontiers in Oncology

Received: 26 November 2020 Accepted: 03 March 2021

Published: 22 March 2021

Citation:

Xie Y, Han Y, Zhang X, Ma H, Li L, Yu R and Liu H (2021) Application of New Radiosensitizer Based on

Nano-Biotechnology in the

Treatment of Glioma.

Front. Oncol. 11:633827.

doi: 10.3389/fonc.2021.633827

\section{Application of New Radiosensitizer Based on Nano-Biotechnology in the Treatment of Glioma}

\author{
Yandong Xie ${ }^{1,2,3 \dagger}$, Yuhan Han ${ }^{1,2,4 \dagger}$, Xuefeng Zhang ${ }^{1 \dagger}$, Hongwei Ma ${ }^{1}$, Linfeng $\mathrm{Li}^{1}$, \\ Rutong $\mathrm{Yu}^{1,2}$ and Hongmei $\mathrm{Liu}^{1,2 *}$ \\ ${ }^{1}$ Institute of Nervous System Diseases, Xuzhou Medical University, Xuzhou, China, ${ }^{2}$ Department of Neurosurgery, The \\ Affiliated Hospital of Xuzhou Medical University, Xuzhou, China, ${ }^{3}$ Department of Neurosurgery, The Affiliated Brain Hospital of \\ Nanjing Medical University, Nanjing Medical University, Nanjing, China, ${ }^{4}$ Department of Neurosurgery, Suqian First People's \\ Hospital, Suqian, China
}

Glioma is the most common intracranial malignant tumor, and its specific pathogenesis has been unclear, which has always been an unresolved clinical problem due to the limited therapeutic window of glioma. As we all know, surgical resection, chemotherapy, and radiotherapy are the main treatment methods for glioma. With the development of clinical trials and traditional treatment techniques, radiotherapy for glioma has increasingly exposed defects in the treatment effect. In order to improve the bottleneck of radiotherapy for glioma, people have done a lot of work; among this, nanoradiosensitizers have offered a novel and potential treatment method. Compared with conventional radiotherapy, nanotechnology can overcome the blood-brain barrier and improve the sensitivity of glioma to radiotherapy. This paper focuses on the research progress of nano-radiosensitizers in radiotherapy for glioma.

Keywords: nano-radiosensitizer, radiotherapy, radiation sensitization, nanoparticles, glioma

\section{INTRODUCTION}

Glioma is a tumor originating from glial cells, which is the most common primary malignant tumor in the brain (1). According to the grade of malignancy listed in the National Comprehensive Cancer Network (NCCN) Guidelines Version 1.2020 Central Nervous System Cancers (CNS), gliomas are classified into grades I to IV. Grade I lesions are benign, including pilocytic astrocytoma, multiform yellow astrocytoma, ganglion glioma, and subependymal giant cell astrocytoma. Grade II tumors include diffuse astrocytomas and oligodendrogliomas, which grow slowly, but can be highly differentiated. However, differing from pilocytic astrocytomas, these tumors infiltrate normal brain tissue and have a tendency to turn malignant. Grade III tumors include anaplastic astrocytoma and oligodendroglioma, which are characterized by high cell density and mitotic cells. The tumors of Grade IV are the most damaged and most common gliomas, including glioblastoma and gliosarcoma. Although we have made many efforts in the past few decades, glioma still has not been cured, and the median survival time of glioblastoma is still only 12 to 15 months (2, 3). The prognosis for patients with recurrent disease remains poor, with a median survival of only 25 and 40 weeks for recurrent glioblastoma (GBM) and recurrent anaplastic glioma, respectively (4). 
Due to the active proliferation of glioma cells and the strong ability of invasive growth, the course of the disease progresses rapidly and is prone to recurrence and spread. As a routine treatment for glioma, radiotherapy has been used in clinical practice since 1970. The $2005 \mathrm{NCCN}$ Glioma Treatment Guidelines recommend radiotherapy as one of glioma standard treatment methods (5-7).

Recently, radiotherapy has been developed rapidly, taking on an increasingly prominent role and position in the treatment of glioma, including conventional radiotherapy, three-dimensional conformal radiotherapy (3D-CRT), intensity-modulated radiation therapy (IMRT), and stereotactic radiotherapy. Conventional radiotherapy for gliomas mostly uses linear accelerators for whole-brain irradiation, which can easily cause damage to normal brain tissue and affect the radiotherapy dose in the tumor area. Radiotherapy technology has gradually shifted from whole-brain radiotherapy to local radiotherapy, together with improvements and research made when applying radiosensitizers, radiation doses, and radiation time intervals, in order to optimize the effect of radiotherapy, inhibit tumor progression, and improve radiation damage. However, radiotherapy for glioma still has some obvious shortcomings. For example, Roshan Karunamuni (8) found that radiotherapy for intracranial tumors can induce cognitive impairment, which is positively correlated with radiation dose. There was no significant difference in 5-year survival between patients with WHO grade II glioma (LGG) in the two groups who received $50.4 \mathrm{~Gy}$ and $64.8 \mathrm{~Gy}$ (9). NCCN recommends the use of preoperative and postoperative MRI imaging to determine the optimal tumor volume (GTV) and clinical target volume (CTV) before radiotherapy for gliomas. The clinical target volume (CTV) is an extension of the GTV (including Grade III gliomas, which increase the margin of 1 to $2 \mathrm{~cm}$, and Grade IV gliomas, which increase the margin of 2 to $2.5 \mathrm{~cm}$ ). Adult lowlevel glioma (WHO I or II) should receive 45-54Gy and $1.8 \mathrm{v} 2.0 \mathrm{~Gy}$ each time. For IDH wild-type low-grade glioma, increasing the RT dose to 59.4-60 Gy was considered. Anaplastic glioma and glioblastoma (WHO grade III or IV) recommend conformal RT (CRT) technology, including threedimensional CRT (3D-CRT) and IMRT for focal brain irradiation, and the recommended radiation dose, with $60 \mathrm{~Gy}$ and $2.0 \mathrm{~Gy}$ each time or $59.4 \mathrm{~Gy}$ and $1.8 \mathrm{~Gy}$ each time. The initial radiotherapy plan was $46 \mathrm{~Gy}$ and $2 \mathrm{~Gy}$ each time.

The mechanism of radiotherapy is mainly divided into two types: direct damage and indirect damage. Direct damage is mainly caused by the direct action of radiation on organic molecules to produce free radicals to cause DNA molecules to break. Indirect damage is mainly caused by the ionization of water in human tissues by radiation (10). More and more studies have shown that the currently used low-liner energy transfer (Low-liner energy transfer LET) radiotherapy may promote the invasion and migration of gliomas (11). The radioresistance of gliomas is an important reason for the limitations of clinical radiotherapy. Rapid proliferation, high invasiveness, and radiation resistance are the main reasons behind unsatisfactory radiotherapy effects for gliomas. How to increase the radiosensitivity of glioma has become an important challenge (12-14).

The emergence of radiotherapy sensitizers provides new opportunities for radiotherapy for glioma. On the one hand, it can enhance the radiosensitivity of tumor cells; on the other hand, it can reduce the radiation dose and the adverse effects of normal brain tissue. When applied with radiotherapy, it can change the responsiveness of tumor cells to radiation, thereby improving the therapeutic efficiency. The killing effect of radiosensitizers on tumor cells is related to many factors, including tumor cell type, degree of cell differentiation, cell cycle, clinical stage, and anatomical classification (15). After treatment with radiation, DNA double-strand break (DSB) and DNA single-strand break (SSB) can be observed. Nevertheless, then some proteins related to DNA repair, such as DNAdependent protein kinase (DNA-PK), and are activated to start the repair process. After that, the damaged cells return to normal cells eventually. In the process of radiation on cells, many factors determine the final results (16). Considering a single cell, it can enhance DNA damage and promote cell apoptosis or autophagy. Substances that inhibit DNA damage repair may enhance the killing effect of radiation on tumor cells to achieve the purpose of radiation sensitization. From the perspective of the tumor as a whole, the oxygen and state of the cells inside the tumor and the cell cycle distribution of the tumor cells have an impact on the killing effect of radiation. Most of the radiosensitizers used in the past refer to drugs with the abovementioned functions. With the continuous development of molecular biology, some small interfering RNA (siRNA) and monoclonal antibodies targeting radiationsensitive genes have become new candidates for radiosensitizers $(17,18)$.

Adams and Fowler et al. divided traditional radiosensitizers into the following categories: DNA precursor base analogs (such as 5-BUdR), electrophilic radiosensitizers (including nitroimidazoles, nitroaromatic hydrocarbons, and nitro heterocyclic compounds), oxygen-like compounds, radiation damage repair inhibitors, mercapto inhibitors (such as 4-ethylmaleimide (NEM), neoarsphenamine, p-chloromer curibenzoate, iodoacetamide), cytotoxic compounds Sensitizer $\left(\mathrm{Cu}^{2+}\right)$, tumor vascular disrupting agent, and gene-related tumor radiosensitizer, etc. $(19,20)$. At present, the conventional radiotherapy sensitizers in clinic include 5-fluorouracil, platinum (such as cisplatin, carboplatin), gemcitabine, etc., which can enhance the radiotherapy sensitivity of tumor cells through different mechanisms of action (such as inhibiting DNA synthesis, promoting DNA double-strand breaks, regulating the cell cycle, etc.) $(21,22)$. However, these conventional radiotherapy sensitizers also have some drawbacks. With the combination of radiotherapy to treat tumors, 5-fluorouracil has a short half-life and requires long-term intravenous drip administration, which easily forms thrombus and causes nosocomial infections (23). Cisplatin is a widely used clinical radiotherapy (CRT) drug, which can kill many types of tumors $(24,25)$. Consequently, it can cause many adverse reactions, such as nausea, vomiting, neurotoxicity, ototoxicity. and 
nephrotoxicity (26). 5-Iodine-2 deoxyuridine (IUdR) has been confirmed to have a significant radiosensitization effect on glioblastoma, but due to the short circulating half-life and the inability to pass the blood-brain barrier (BBB), its clinical application is limited (27). DNA double-strand repair inhibitors (DSBRIs) KU55933 were once considered as one of the most promising drugs to improve radiotherapy, but its clinical application remains due to its potential toxicity to normal tissues, inability to select-enter tumor cells, and poor solubilization (28). Misonidazole is a hypoxic cell sensitizer, which can enhance the antitumor effects of cyclophosphamide in preclinical studies (29). Formerly, it is expected to be an ideal radiotherapy sensitizer in terms of controlling radiation-resistant tumor cells and p53 mutant tumor cells (30). However, researchers in a randomized study found that Misonidazole did not improve the prognosis of cervical cancer radiotherapy compared with the placebo group (31), making people question the effectiveness of Misonidazole, with the toxicity of Misonidazol further studied. Trans sodium crocetinate (TSC) has been verified as a radiotherapy sensitizer. In a study of a C6 glioma model, the use of TSC improved the regression of GBM tumors after radiotherapy, increased survival, and achieved radiosensitization. The mechanism of action may temporarily increase tissue oxygenation of hypoxic glioma (32, 33). However, the effect on patients with glioma needs to be further explored. Carbon ion radiotherapy is an excellent way of radiotherapy, with great application prospects in glioma (3436). However, its combination with nano-radiosensitizers remains to be studied.

Therefore, how to find a safe and effective radiotherapy sensitizer for glioma has become an urgent problem. With the rapid development of nano-science and technology, people are paying more and more attention to the role of nano radiation sensitizers in the treatment of glioma. Therefore, this paper will review the principle and types of radiosensitizers in radiotherapy for glioma and the research progress of radiosensitizers in radiotherapy for glioma

\section{ADVANTAGES OF NANO- RADIOSENSITIZERS IN RADIOTHERAPY FOR GLIOMA}

Nanomaterials have been widely used to improve the efficacy of radiotherapy due to their good biocompatibility, inherent radiosensitivity, a high carrying capacity of multiple drugs, and enhanced penetration and retention in tumor tissues $(37,38)$. The research of nanomaterial-mediated sensitization of radiotherapy mainly focuses on the use of high atomic number nanoparticles (such as gold, silver, and bismuth) to enhance the radiation energy deposition in cells. With the development of polymer nanomaterials, the research on the treatment of glioma is increasing gradually. Small molecule drugs can be chemically bound and physically coated to target glioma tissues through the blood-brain barrier, thus improving the efficacy of radiotherapy for glioma.

\section{Nano-Radiotherapy Sensitizers Can Efficiently Cross the BBB and Target Gliomas}

The blood-brain barrier (BBB) is the outer layer of blood vessels in the brain and spinal cord, which is highly selective for substance penetration. The barrier properties of a healthy blood-brain barrier are mainly due to the tight junctions between endothelial cells, which are stable by astrocytes and pericytes. Through complex design, the blood-brain barrier can prevent the passage of neurotoxins and microorganisms, and selectively allow oxygen and nutrients to enter the central nervous system, thereby maintaining homeostasis (39-44). $\mathrm{BBB}$ restricts the delivery of chemical drugs and becomes a difficult point in the chemotherapy of glioma. Therefore, the primary problem that nano-radiosensitizers used in radiotherapy for glioma need to solve is to cross the BBB and target the glioma tissue. Normally, nanoparticles cannot pass through the $\mathrm{BBB}$, but when the tumor is present, $\mathrm{BBB}$ permeability increases, and nanoparticles can pass through. Compared with normal tissues, tumor tissues have an abundant blood supply, wide vascular space, and lack lymphatic drainage, making macromolecular substances or lipid particles have high permeability and high retention effects in tumor tissues, which can be called the high permeability and retention effect (EPR) of solid tumors. It can increase the drug concentration in tumor tissue through the EPR effect, which is passive transport. Our research group (45) used this effect to design an RT-sensitive liposome that is responsive to hypoxia as a novel DOX delivery system. The hypoxia radiosensitizer nitroimidazole combines with lipid molecules with hydrolysable ester bonds to form $\mathrm{MDH}$, which is mixed with DSPE-PEG2000 and cholesterol to make MLP liposomes. Experimental results show that MLP liposomes can carry DOX and nitroimidazole across the BBB and can effectively stay in the tumor area. Hypoxia can induce the conversion of hydrophobic nitroimidazole into hydrophilic aminoimidazole through electron transfer, causing the instability of liposomes and releasing DOX. Meanwhile, MI enhanced the radiosensitivity of radiation-tolerant hypoxic cells due to electron affinity, and DNA damage caused by ionizing radiation was enhanced. The drug delivery system can effectively inhibit the growth of C6 glioma cells by combining radiotherapy and chemotherapy. Additionally, nano-radiotherapy sensitizers actively cross $\mathrm{BBB}$ by adding special ligands, antiboding and proteining to the surface engineering of nanoparticles to form multifunctional nanoparticles, with a strong BBB crossing efficiency and can selectively and specifically target CNS tumor tissues (46). It should be noticed that there is another Nano-radiotherapy sensitizer that was designed by our group called ALP-(MIs)n/DOX, and it also has an excellent ability to cross the BBB (47) (Figure 1). Zhang et al. (48) encapsulated the cyclin-dependent kinase inhibitor dinaciclib into lipid nanoparticles containing anti-PD-L1 antibodies, and RT induced the up-regulation of PD-L1 in glioma infiltrating TAMC (Tumor-associated myeloid cells). Lipid nanoparticles (LNP) targeting PD-L1 effectively target glioma tissues, inhibit PD-L1 or eliminate TAMCs, which are immunosuppressive 
A

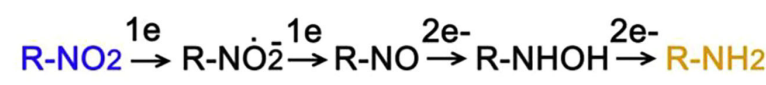

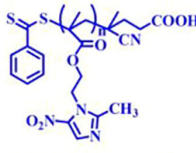

ताIIT hydrophobic P-(Mls)n

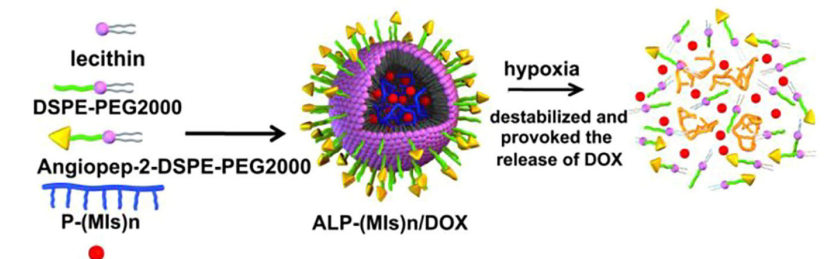

DOX

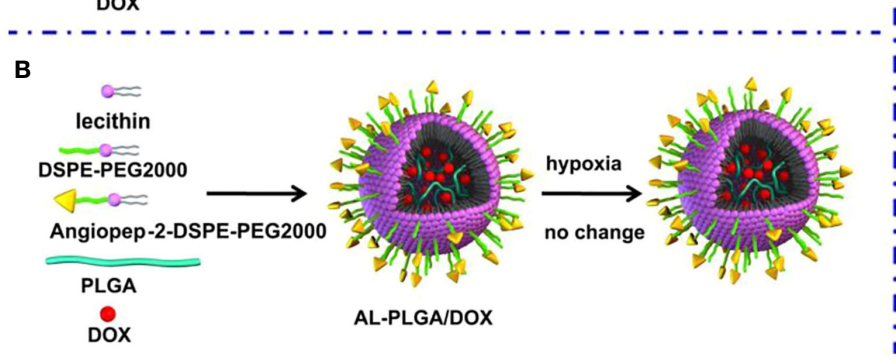

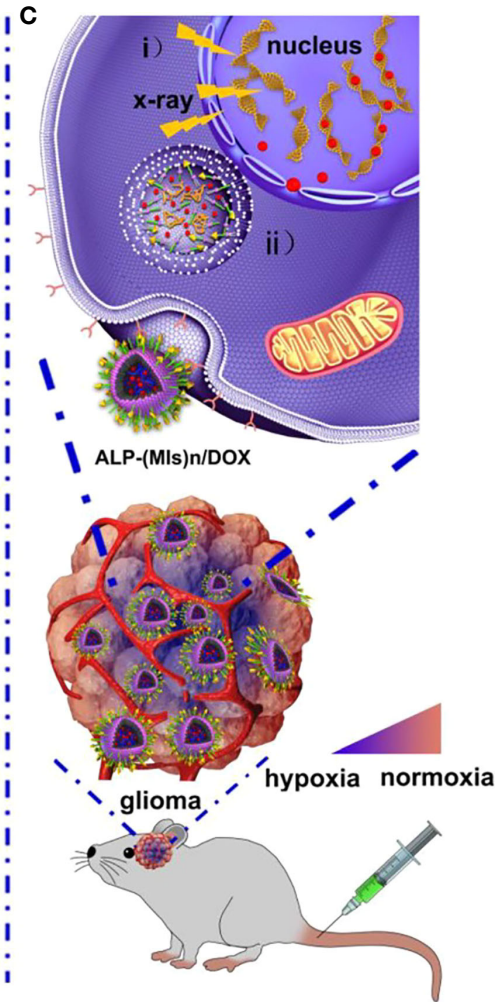

FIGURE 1 | Schematic of the hypoxia-responsive and hypoxia RT sensitization ALP-(MIs)n drug-delivery system. (A) Mechanism of ALP-(MIs)n RT sensitization and DOX release under hypoxic condition and formation of ALP-(Mls)n/DOX. Six electrons are transferred in the complete reduction of nitro $\left(\mathrm{R}-\mathrm{NO}_{2}\right)$ to amine $\left(\mathrm{R}-\mathrm{NH}_{2}\right)$ under hypoxic conditions via a single-electron reduction catalyzed by a series of intracellular nitro reductases. (B) Formation of AL-PLGA/DOX as the control group. (C) Schematic illustrating ALP-(MIs)n applications: (i) Hypoxic cell radiosensitizer. ii. Hypoxia-responsive release of DOX into the cytoplasm, and then transports it to the nucleus to kill tumor cells (47).

cells, strengthen anti-tumor immunity, and extend the survival time of mice.

\section{Enhance the Efficacy of Radiotherapy for Glioma Through Radiation Energy Deposition}

In terms of sensitization of radiotherapy, metal nanoparticles have been studied for many years as radiotherapy sensitizers. Metal nanoparticles with a high $\mathrm{Z}$ value have a high absorption capacity of radiation and can concentrate radiation energy on the tumor site (49). It is generally believed that these nanoparticles increase the cross-section of tissues or cells that react with radiation, facilitating the efficient deposition of high-energy radiant energy. From the formula of X-ray absorption coefficient $\mu$ and incident $X$-ray energy $\mathrm{E}$ and atomic coefficient $\mathrm{Z}: \mu=\rho \mathrm{Z}^{4} /\left(\mathrm{AE}^{3}\right)$, the absorption coefficient $\mu$ is positively related to the fourth power of atomic coefficient $Z$, where $\rho$ is the density and $A$ the atomic mass $(50,51)$. Therefore, materials with high atomic coefficient elements have better X-ray energy absorption. The high $\mathrm{Z}$-value nanoparticles after absorbing ray energy can produce a photoelectric effect, Compton effect, and Auger effect; this then generates a series of secondary electrons, such as the photoelectron, Compton electron, and Auger electron (52-54), which can directly interact with biomolecules locally or generate large amounts of ROS with water molecules. The principium above is shown in Figure 2 (71). Tumor cells are then killed and the sensitization of radiotherapy is enhanced. The radiosensitization effect of AuNPs

\section{Interaction of X-ray with High-Z Materials}

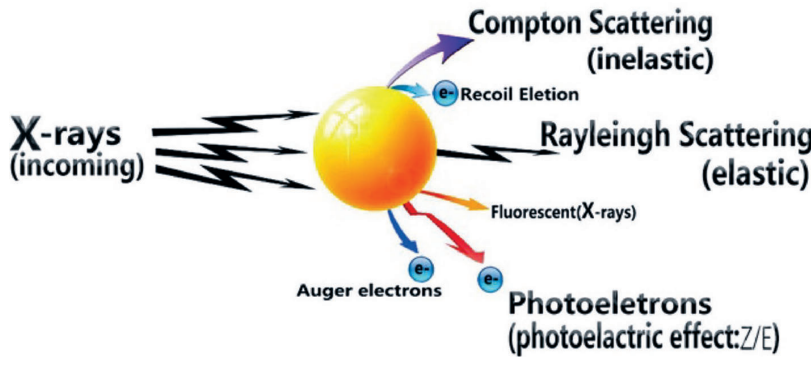

FIGURE 2 | Radiant energy deposition to arouse secondary electrons (71). 
depends on its size and the type of surface modification $(55,56)$. Silver, platinum, gadolinium, etc. have similar radiosensitization effects to gold nanomaterials. Liu et al. found that malignant glioma-bearing rats treated with silver nanoparticles (AgNPs) after radiotherapy effectively inhibited the proliferation of cancer cells and promoted the apoptosis of cancer cells (57).

\section{Enhance Radiotherapy for Glioma by Enhancing DNA Damage and Inhibiting DNA Repair}

The radiotherapy resistance of tumors is mainly manifested in the double-strand breaks of tumor cells caused by radiation, and DNA itself has the ability to repair double-strand breaks (59). It is believed that the anti-radiation effect of tumors is due to hypoxia in tumor regions, which reduces DNA damage and enhances cellular defense mechanisms $(60,61)$. Therefore, DNA damage in glioma cells can be increased by increasing the oxygen content in the glioma region. In the meantime, the local oxygen of the tumor is more likely to produce ROS under the action of radiation, which increases the killing effect on the tumor. Many nano-radiotherapy sensitizers work by increasing the oxygen content of the tumor area $(62,63)$. Additionally, gliomas are usually resistant to RT due to their strong DNA repair activity $(64,65)$. The cytotoxicity of RT is mainly due to DNA damage, and double-strand breakage (DSB) caused by RT is the most serious type of DNA damage. If it is not repaired, it is deadly to the cells (66). Nanoparticles can inhibit DNA repair by inducing down-regulation of repair proteins, such as thymidylate synthase (67) (Figure 3), or inhibiting the DNA damage repair signaling pathway (68), thereby increasing the effect of radiotherapy. In terms of glioma, our research group designed a hypoxic radiosensitizer-prodrug liposome (MLP) as a carrier for the DNA repair inhibitor Dbait, which significantly inhibited the growth of glioma in situ in mice with the combination with radiotherapy (69).

\section{Can Effectively Transport Radionuclides to Achieve RIT}

Radiotherapy is divided into two categories: external radiation therapy (EBRT) and internal radioisotope therapy (RIT). For EBRT, radiation beams such as high-energy X-rays, electron beams, or proton beams from outside the body are directly irradiated on the tumor, thereby inducing the death of cancer cells. For RIT, a minimally invasive method is used to introduce therapeutic radioisotopes into the tumor, such as direct infusion via a catheter (also called brachytherapy) $(70,71)$. Brachytherapy is not suitable for treating distant tumors due to the rapid elimination of radioisotopes in vivo. The combination of targeted nanoparticles with radioactive isotopes enables accurate isotope delivery, while nanoparticles for internal radiotherapy can also improve tumor vascular permeability, enhance retention effect (EPR), and increase uptake of the next wave of nanoparticles (38). In the treatment of glioma, nanoparticles were also widely used to deliver radionuclides $(58,72)$, which was proven to have good safety and feasibility (73). Allard introduced a lipid nanocapsule (LNC), which encapsulated ${ }^{188} \operatorname{Re}\left({ }^{188} \operatorname{Re}\left(\mathrm{S}_{3} \mathrm{CPh}\right)_{2}\left(\mathrm{~S}_{2} \mathrm{CPh}\right)\left[{ }^{188} \mathrm{Re}-\mathrm{SSS}\right]\right)$ to form a lipophilic complex that can be used as a new type of
A

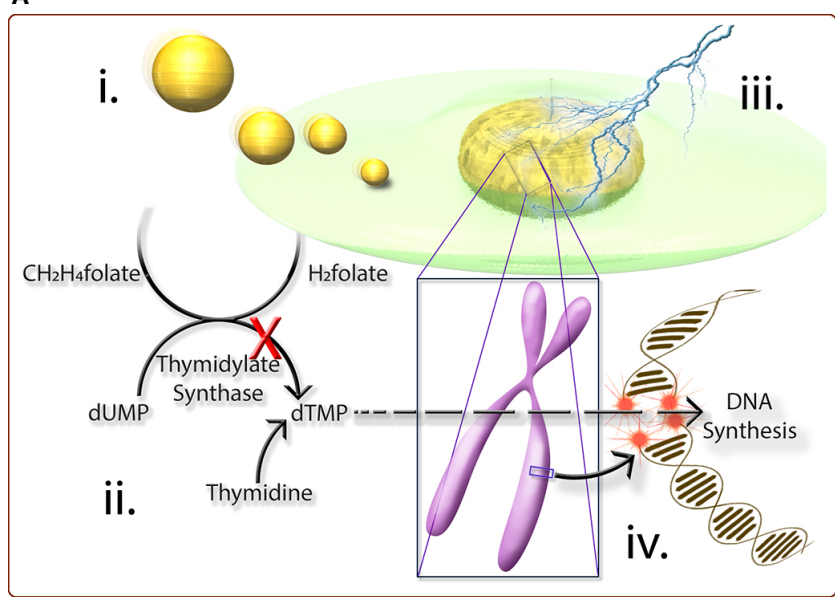

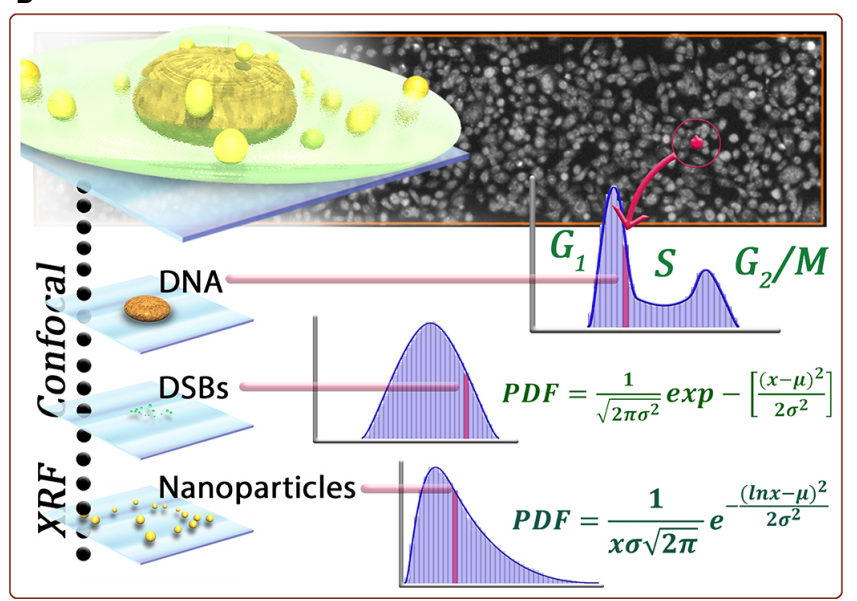

FIGURE 3 | (A) Schematic representation of the following conceptst: (i) internalization of nanoparticles by cells can lead to the down-regulation of proteins, including thymidylate synthase (TS), important for DNA damage repair response; ii. due to the down-regulation of TS, the conversion of dUMP to dTMP is inhibited; iii. subsequently, when the DNA is subjected to insult by ionizing radiation causing doublestrand breaks; and iv. the normally effective homologous recombination pathway for repairing DSB's in S-phase cells is also inhibited, leading to a biological mechanism of radiosensitization. (B) A cross-correlative methodology developed provides a three-dimensional data set to compare cell populations and sub-populations with regard to nanoparticle dose-response at the single-cell level. Correlating biological markers imaged with laser scanning confocal microscopy with elemental content from synchrotron X-ray fluorescence microscopy for cell populations provides statistically significant, descriptive analysis of cell populations with regard to biological response for a quantified number of nanoparticles. For example, only cells with comparable numbers of nanoparticles are compared, or only cells in a certain phase are compared. The population behavior can be described by fitting functions and any individual cell from a population can be characterized by its biological markers coupled with its nanoparticle content (67). 
radiopharmaceutical carrier. The results showed that the median survival of rats treated with $8 \mathrm{~Gy}^{188} \mathrm{Re}$-SSSLNC was significantly improved. Compared with the control group, the median survival time increased by about $80 \%$, with $33 \%$ of long-term surviving animals and when administered in $\mathrm{LNC},{ }^{188} \mathrm{Re}$ tissue retention was greatly prolonged, with only $10 \%$ of the injected dose being eliminated at $72 \mathrm{~h}$ (74). Interestingly, another study revealed that $188 \mathrm{Re}$-activity gradient led to a bypass of immunosuppressive barriers, which can be used to treat glioblastoma (75).

\section{Nano-Radiotherapy Sensitizer Combined With Other Treatment Methods to Treat Glioma}

Nano-radiotherapy sensitizers can not only be enriched at the tumor site by enhancing the penetration and retention effects and improving the targeting effect on tumor tissues, but they also can be combined with chemotherapy, immunotherapy, and other treatment methods. Meanwhile, the specific microenvironment of glioma is used to achieve effective drug delivery (76), improving the therapeutic effect of glioma.

Nano-radiotherapy sensitizer in combination with immunotherapy uses nano-delivery of inhibitory antibodies to block immune checkpoints. Due to the ability of nanomaterials to penetrate the $\mathrm{BBB}$, immune-stimulating nanoradiation sensitizers can penetrate the $\mathrm{BBB}$ well and accumulate in glioma tissues. As mentioned above, lipid nanoparticles containing PD-L1 antibody not only have targeted functions but also inhibit PD-L1 and enhance T cell anti-tumor immunity and kill glioma cells in synergism with radiotherapy (48) (Figure 4). In addition, nanomaterials used as photosensitizers combined with photodynamic therapy (PDT) for radiotherapy have achieved significant effects on some other types of tumors $(77,78)$, which can also similarly kill glioma cells (79). In a study of high-grade glioma treatment, we found that photodynamic therapy (PDT) extended survival in patients, and in combination with intraoperative radiation therapy (IORT), improved survival even further (80). However, the application of nanophotosensitizer combined with PDT to the radiotherapy for glioma has not been reported in the literature.

Researchers found that enhanced autophagy of glioma promoter cells (GICs) contributes to the elimination of radiotherapy resistance (81). Liu et al. evaluated the radiosensitization effect of silver nanoparticles (AgNPs) on hypoxic glioma cells and found that the radiosensitization ability of AgNPs in hypoxic U251 cells and C6 cells was higher than that of normoxic U251 and C6 cells (82). The main reason for hypoxic radiation sensitization induced by siNPS is the promotion of cell apoptosis and the enhancement of destructive autophagy, suggesting that AgNPs can be used as excellent radiosensitizers in the treatment of hypoxic glioma. Paradoxically, earlier studies have found that gamma-rayinduced autophagy contributes to the radioresistance of these cells, and autophagy inhibitors may be employed to increase the sensitivity of GSCs to gamma-radiation (83).

Autophagy has a protective effect on inhibiting the radiosensitization of STAT3. Inhibition of autophagy and STAT3 may be a potential therapeutic strategy to improve the radiosensitization of glioma cells (84). Therefore, the effect of autophagy on radiosensitization of gliomas is still controversial $(85,86)$.

Emerging nano-radiosensitizers have developed rapidly currently. For example, near-infrared light combined with radiotherapy that converts light energy into heat energy (87), sonoporation sensitization radiotherapy (88), and nanoparticles of heterojunction structure can avoid the recombination of electrons and holes, improve photocurrent and photocatalytic activity, etc. (89).

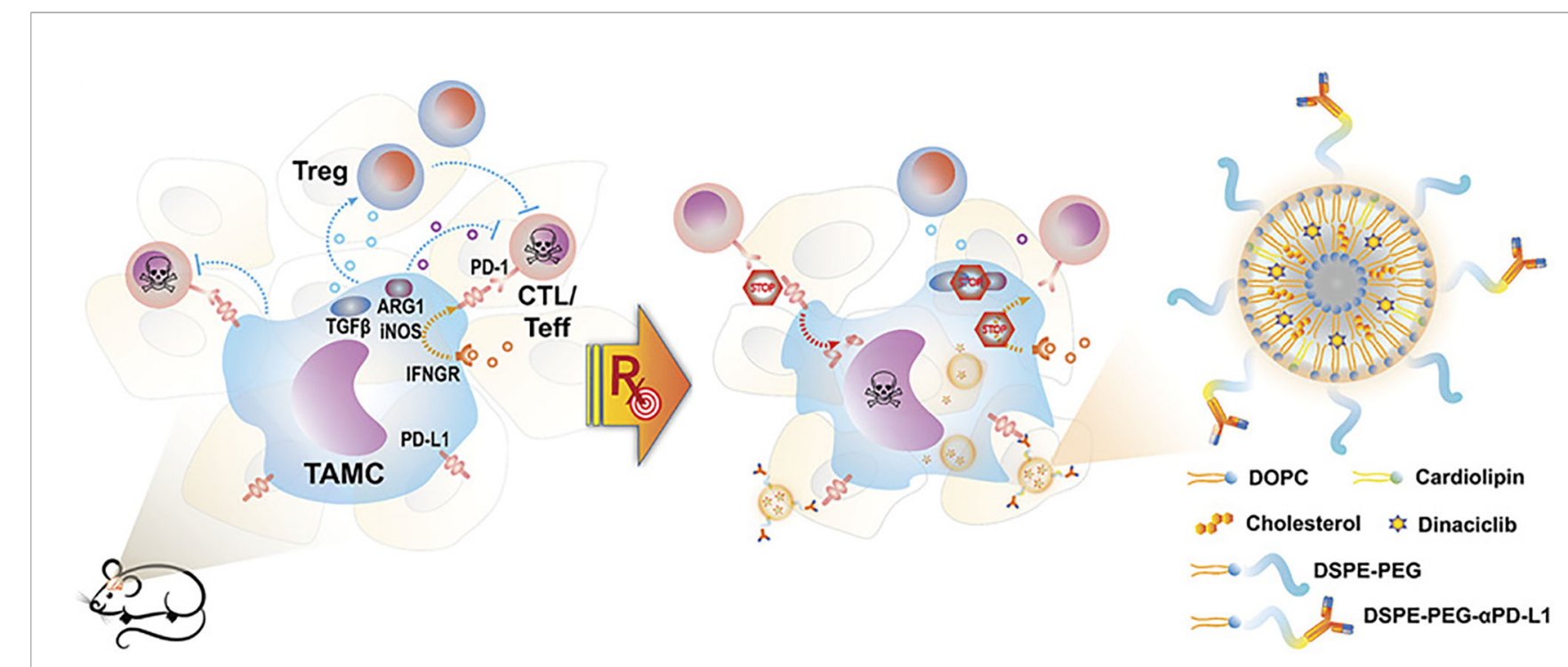

FIGURE 4 | Schematic representation of nano-targeting of glioma-associated TAMCs. (CTL, cytotoxic T lymphocyte; Teff, effector T cell; PD-1, programmed cell death protein 1; IFNGR, IFN gamma receptor) (48). 


\section{THE MAIN TYPES OF NANO- RADIOSENSITIZERS IN THE TREATMENT OF GLIOMAS}

Nano-radiotherapy sensitizers can overcome a series of problems such as high toxicity, non-specificity, and obvious side effects of traditional sensitizers, making nano-radiosensitization treatments become a popular treatment for various malignant tumors including gliomas. According to the physicochemical properties of nano-sensitizers in existing research, the common nano-sensitizers (nanoparticles) in the treatment of glioma are divided into the following categories: 1 . High- $\mathrm{Z}$ metal nanoradiotherapy sensitizers; 2 . Common metal and its oxide nanoradiotherapy sensitizer; 3 . Semiconductor nano-radiotherapy sensitizer; 4. Non-metallic nano-radiotherapy sensitizer material; and 5. Multifunctional nano-radiotherapy sensitizer. We draw a diagram (Figure 5) which summarizes the main species of nano-radiosensitizers and more details are shown in Table 1.

\section{High-Z Metal Nano-Radiosensitizer}

A high- $Z$ metal nano-radiotherapy sensitizer is the most indepth research among various nano-material sensitizers because high- $Z$ elements have a strong X-ray attenuation ability (50), which can increase the radiation dose of tumor cells in GBM tissues, thereby achieving the therapeutic effect of sensitization of radiotherapy (90). Gold, silver, platinum, and other high- $\mathrm{Z}$ precious metals have the advantages of low toxicity, easy preparation, controllable size and morphology, easy surface functionalization, high chemical stability, and good biocompatibility (91), which have natural advantages of of preparing bio-related nanomaterials. Recently, gold nanomaterials, the most studied among high $\mathrm{Z}$ metals, have been widely used in radiosensitization therapy of glioma (92). Yan Liu et al. used a one-pot green syn-thetic method to synthesize luminescent gold nanoclusters (AuNC) (93). SuYang Yang et al. used the strategy of cross-linked stable lipid nanocapsules (NCs) as a carrier to prepare a kind of intermembrane cross-linked multilayer lipid vesicle (ICMV) containing amphiphilic gold nanoparticles (amph-NPs) to form $\mathrm{Au}-\mathrm{NCs}$. In vivo experiments on mice showed that the AU-NCS combined radiotherapy group had an obvious tumorkilling effect compared with the radiotherapy alone group (94). Yijin Liu et al. studied a mixed anisotropic nanostructure composed of gold $(\mathrm{Au})$ and titanium dioxide $\left(\mathrm{TiO}_{2}\right)$. As a radiosensitizer, $\mathrm{Au}-\mathrm{TiO}_{2}$ nanoparticles (DAT) can significantly enhance the effect of radiotherapy $(77,93)$. In addition to nanogold, nano-silver and nano-platinum materials have also been extensively studied (95). Haiqian Zhang et al. prepared a silver nanoparticle (AgNPs) for radiosensitization of hypoxic glioma cells, with the results showing that AgNPs can significantly improve the effect of radiotherapy in the radiotherapy of hypoxic glioma (82). Eva Pagá cová et al. analyzed effects on radiation-induced $\gamma \mathrm{H} 2 \mathrm{AX}+53 \mathrm{BP} 1$ lesions of different nanoparticle materials (platinum $(\mathrm{Pt})$ and gold $(\mathrm{Au})$ ), cancer cell types (HeLa, U87, and SKBr_3), and low-line energy transfer

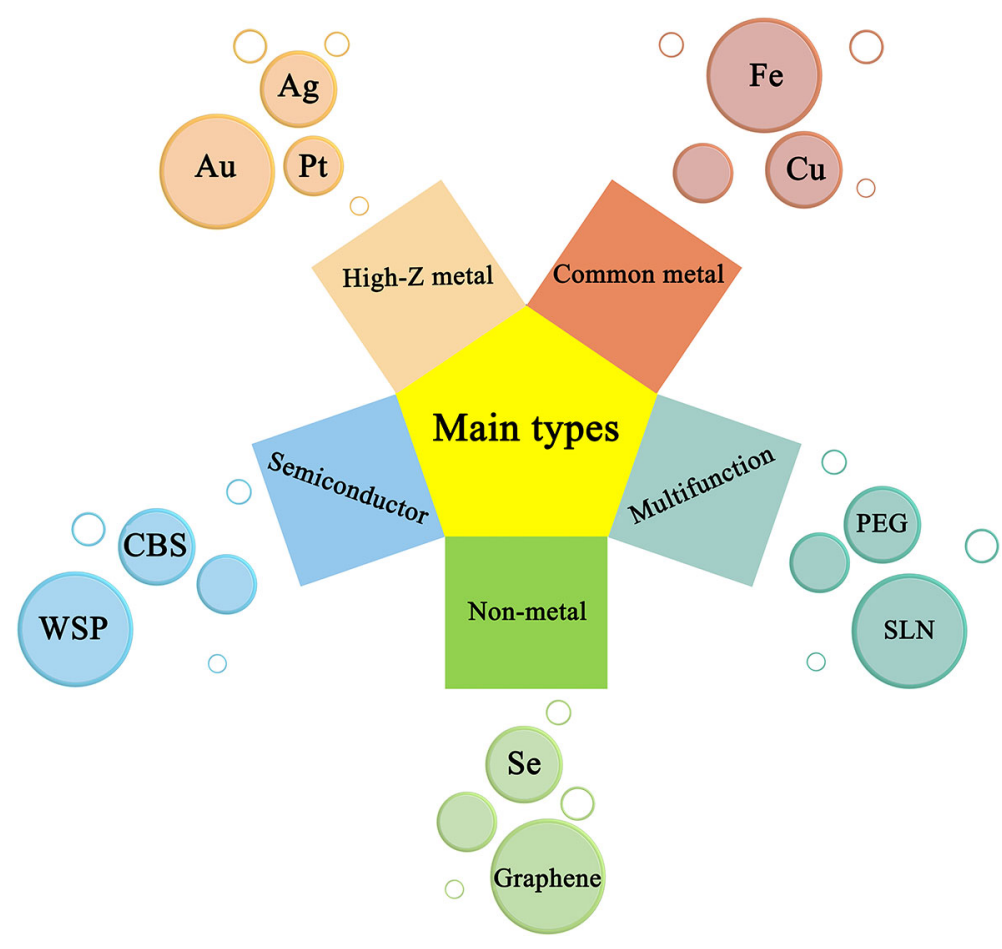

FIGURE 5 | Representative nanomaterials and basic principles of action under types of nanoradiosensitizers. 
TABLE 1 | Lists the types of glioma nano-radiotherapy sensitizers mentioned in the paper, including the type, name, and position of sensitizers.

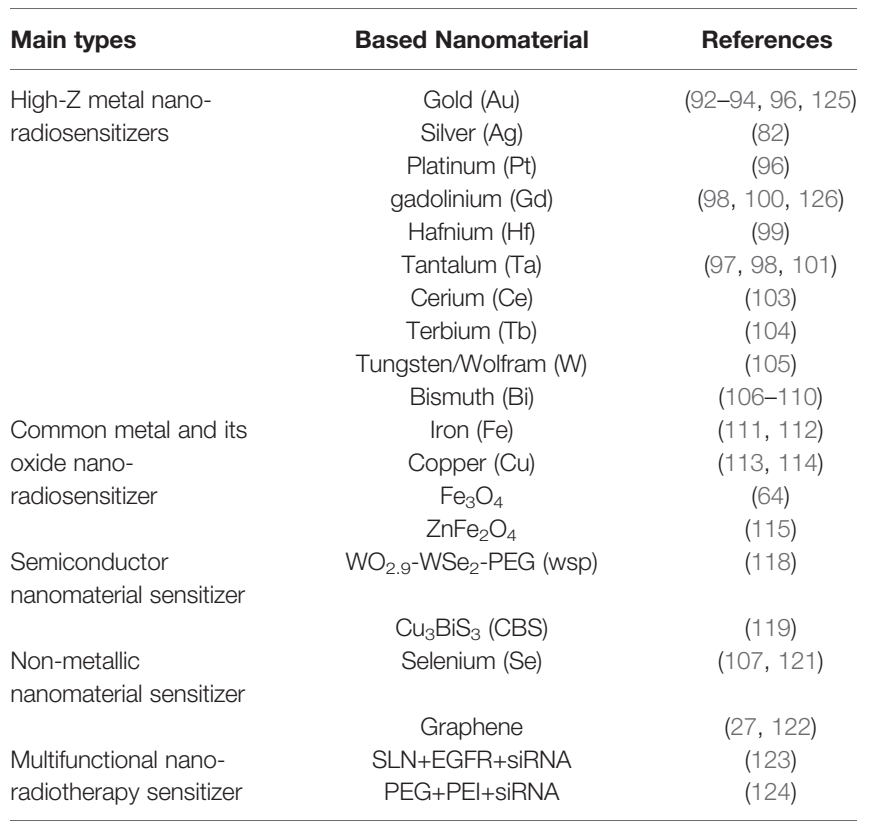

(LET) ionizing radiation ( $\gamma$ - and X-rays) dose (up to $4 \mathrm{~Gy}$ ) to evaluate its radiosensitization effect in gliomas (96). In addition to the above high- $Z$ precious metals, other high- $Z$ metal nanosensitizers also include gadolinium (Gd), hafnium (Hf), tantalum ( $\mathrm{Ta})$, cerium $(\mathrm{Ce})$, terbium $(\mathrm{Tb})$, tungsten $(\mathrm{W})$, bismuth (Bi), and other metal elements with large atomic coefficients (97). Particularly, lanthanide metal-based nanoparticles are being developed and utilized due to their strong X-ray attenuation ability. Verry, $\mathrm{C}$ et al. designed a gadolinium (Gd)-based AGuIX nanoparticle for combined radiotherapy for patients with brain metastases, showing that the nanoparticle significantly improved the effect of radiotherapy $(98,99)$. Chen has developed a nano-sensitizer of titanium dioxide doped with gadolinium, which targets mitochondria for effective radiation therapy. With X-ray irradiation, nanosensitizers trigger the domino effect of ROS accumulation in mitochondria (99). Géraldine et al. used 9L glioma cell line (9LGS) tumor-bearing mice to inject a biodegradable gadolinium-based ultrafine nanoparticle (AGuIX nanoparticles) intravenously. They found that AGuIX particles do not leak out of normal blood vessels, allowing more particles to accumulate effectively in glioma tissue, increasing the sensitivity of radiation therapy $(100,101)$.

In addition to the metal gadolinium (Gd), the metal hafnium (Hf), as a high-Z metal, is often used in the X-ray manufacturing industry because it easily emits electrons. Pure hafnium has the advantages of plasticity, easy processing, high temperature resistance, corrosion resistance, and so on. It is an important material in the atomic energy industry, which has also been put into medical research and use. Min-Hua Chen proposed a nanoparticle that can enhance active oxygen: Hf-doped hydroxyapatite (HF: HAP). After exposing (HF: HAP) to gamma rays, the generation of ROS in the cell increases significantly (99). Jin J summarized the latest progress in radiation therapy (RT) and immunotherapy of nanoparticles (NPs) such as hafnium (Hf) and bismuth (Bi) and evaluated the feasibility of high-Z metals as nano-radiosensitizers (102).

Among high- $Z$ metals, tantalum (Ta) has been widely used in the medical field because of its moderate hardness and excellent ductility. The excellent corrosion resistance is mainly due to the formation of $s$ atable tantalum pentoxide $\left(\mathrm{Ta}_{2} \mathrm{O}_{5}\right)$ protective film on the surface, which has also been used in the field of radiotherapy for glioma sensitization. Briggs discovered for the first time that tantalum $\left(\mathrm{Ta}_{2} \mathrm{O}_{5}\right)$ nanoparticles showed a doseenhancing effect on gliosarcoma cells with strong radiation resistance under $10 \mathrm{MV}$ irradiation. It is believed that the enhancement effect is due to the secondary electrons generated by the photoelectric effect, which increases the biological effect of radiation, indicating that tantalum $\mathrm{Ta}_{2} \mathrm{O}_{5}$ has a certain radiosensitization effect in the radiotherapy for glioma (101). Besides, cerium $(\mathrm{Ce})$ is also a widely used high- $\mathrm{Z}$ metal in the medical field as the most abundant rare earth element in the earth's crust. Xiaoyan Zhong prepared $\mathrm{Ce}(\mathrm{Ce})$-doped $\mathrm{NaCeF}_{4}$ : $\mathrm{Gd}$ and $\mathrm{Tb}$ fluorescent nanoparticles (SCNP or fluorescent scintillator). Due to the sensitization of $\mathrm{Ce}$ ions, $\mathrm{Tb}$ ions can trigger X-ray sensitive fluorescence (XEF) under X-ray irradiation to generate reactive oxygen species (ROS) in RDT, thereby increasing the sensitivity to radiotherapy (103). Runowski enriches the fluorescence effect of $\mathrm{CeF}_{3}$ nanoparticles (NPs) by co-doping with $\mathrm{Tb}^{3+}$ and $\mathrm{Gd}^{3+}\left(\mathrm{CeF}_{3}: \mathrm{Gd}^{3+}, \mathrm{Tb}^{3+}\right)$ for the treatment of deep tumors such as intracranial tumors (104).

As a new high-tech material, tungsten (W) is another high- $Z$ metal that has been put into the medical field. According to Wang, J's research, tungsten sulfide ( $\mathrm{WS}_{2} \mathrm{QDs}$ ) is a nanomaterial suitable for radiotherapy (RT) and photothermal therapy (PTT), proving that tungsten (W) can be used as a nanoradiosensitizer (105).

Bismuth (Bi) is a hot spot nano-radiotherapy material besides nano-gold materials. Hossain, $\mathrm{M}$ controlled the concentration of nanoparticles to $350 \mathrm{mg} \cdot \mathrm{g}-1$ under a radiation source of $50 \mathrm{kVp}$ and found that the radiosensitization effect of nano-bismuth was 1.25 times and 1.29 times stronger than that of nano-gold and nano-platinum, respectively. Based on this, it is concluded that bismuth nanoparticles have a stronger sensitizing effect than gold and platinum nanoparticles with the same nanometer size, particle concentration, and action site (106). In the presence of bovine serum albumin (BSA), Fangxin Mao et al. synthesized ultra-small biocompatible $\mathrm{Bi}_{2} \mathrm{Se}_{3}$ nanoparticles by reacting hydroxyethylthioselenide and bismuth chloride in an aqueous solution $\mathrm{BSA}-\mathrm{Bi}_{2} \mathrm{Se}_{3}$ shows a strong wide absorption rate, high light-to-heat conversion efficiency, and a strong radiation sensitization effect in the near-infrared (NIR) window (107). Huan Yu et al. synthesized bismuth sulfide nanoparticles (BiNP) and coupled them with immunoactive Ganoderma lucidum polysaccharide (GLP) and verified that GLP-BiNP has a dual role in tumor treatment through radiosensitization and immune activity (108). Guosheng Song used a partial cation exchange method, which took MnSe nanocrystals as a template to replace 
manganese with bismuth in the outer layer to form a $\mathrm{Bi}_{2} \mathrm{Se}_{3}$ shell, to advance the blood supply of tumor tissue, increase oxygenation significantly, improve the effect of radiotherapy (RT), and kill tumor cells effectively (109). Fangmei Zhang et al. designed and prepared a multifunctional bismuth-based nano-olfactory, which was functionalized by S-nitrosothiol and named Bi-SNO (NPs). X-rays can break down the S-N bond and trigger the release of a large amount of NO (over $60 \mu \mathrm{M}$ ). The prepared Bi-SNO (NPs) with a small volume $(36 \mathrm{~nm})$ has the ability to absorb and convert $808 \mathrm{~nm}$ near-infrared photons for photothermal treatment, as well as the ability to increase X-ray absorption and CT imaging sensitivity. Moreover, the synergistic effect of Bi-SNO radiation, photothermal, and gas therapy in vivo was further studied, to get a significant synergistic tumor inhibition effect (110).

\section{Common Metal and Its Oxide Nano-Radiosensitizer}

Other common metal types with nanoradiosensitization effects include common non-high $\mathrm{Z}$ nanoradiosensitizers, such as nanoradiosensitizers, iron nanoradiosensitizers, and copper nanoradiosensitizers. Chengcheng Yang developed a polydopamine (PDA) coated Ge11 peptide conjugated iron oxide nanoparticles (Ge $\mathrm{Ge}_{11}$-PDA-Pt@USPIOs) with cisplatin as a carrier, based on ultra-small superparamagnetic iron oxide nanoparticles (PAA@USPIos) coated with polyacrylic acid, showing synergistic therapeutic effects of radiotherapy and chemotherapy under low temperature in vitro (111). Muhammed prepared $\mathrm{SiO}-\mathrm{MNP}$-coated iron oxide nanoparticles by coprecipitation and other methods to enhance the radiation sensitization effect by increasing the production of ROS (112).

For nano-copper sensitizers, Yu Fan et al. designed a therapeutic nano-platform based on the complexation of pyridine (Pyr) functionalized fifth-generation $\left(G_{5}\right)$ polyamidoamine dendrimers with $\mathrm{Cu}^{2+}$, which is used for radio-enhanced T1-weighted magnetic resonance (MR) imaging and coordinated radiotherapy and chemotherapy for tumors and tumor metastases (113). Chenyang Zhang designed a new smart radiosensitizer based on $\mathrm{Cu}_{2}(\mathrm{OH}) \mathrm{Po}_{4}$ nanocrystals. Sensitizers can respond to both endogenous $\left(\mathrm{H}_{2} \mathrm{O}_{2}\right)$ and exogenous (X-rays) stimuli simultaneously and can finally induce apoptosis and necrosis of cancer cells (114).

Some ferrite-based spinel structure nano-material sensitizers have also been reported. For example, Alireza Meidanchi synthesized superparamagnetic zinc ferrite spinel nanoparticles $\mathrm{ZnFe}_{2} \mathrm{O}_{4}$ by a hydrothermal method which is used as a radiosensitizer for cancer treatment. When exposed to gamma rays, the low-energy electrons produced in the nanoparticles further kill tumor cells. The use of biocompatible $\mathrm{ZnFe}_{2} \mathrm{O}_{4}$ nanoparticles (at a concentration of $100 \mu \mathrm{g} / \mathrm{ml}$ ) in radiotherapy can produce a synergistic response to radiotherapy. The killing efficiency of highly radiation-resistant cancer cells is 17 times that of traditional radiotherapy, so it is a reliable radiation sensitizer (115). Besides, the sensitizers of metal nanomaterials for glioma include some special new nanometal materials, such as metal-organic skeleton (Zr-MOF) nanoparticles (116) and room temperature liquid nanometals (LMs) (117). Moreover, some of the above nano metal materials not only directly affect the sensitization of radiotherapy but also act as multifunctional adjuvants in auxiliary imaging, such as X-ray diagnosis (116).

\section{Semiconductor Nanomaterial Sensitizer}

In the field of semiconductor nanosensitizer materials, common semiconductor materials include silicon $(\mathrm{Si})$, germanium $(\mathrm{Ge})$, gallium arsenide (GaAs), and other compound semiconductors doped or made into other compound semiconductor materials. Among them, silicon is the most commonly used semiconductor material. Semiconductors have the following in common. The conductivity of a semiconductor is between a conductor and an insulator, which will change significantly when it is stimulated by external light and heat. Therefore, semiconductor materials have great potential in the application of sensitization of radio therapy. Dong Xinghua et al. discovered $\mathrm{WO}_{2.9}$-WSe $\mathrm{W}_{2} \mathrm{PEG}$ semiconductor heterojunction nanoparticles (WSP NPs), which can be combined with radiotherapy (RT), photothermal therapy (PTT), and immune checkpoint suppression therapy (CBT) to jointly enhance anti-tumor and anti-metastasis effects. Under X-ray irradiation, the nanosystem catalyzes the highly expressed $\mathrm{H}_{2} \mathrm{O}_{2}$ in TME, promotes the generation of non-oxygen-dependent reactive oxygen species, and enhances the effect of radiotherapy (118). Yiwei Kang et al. encapsulated small semiconductor copper bismuth sulfide $\left(\mathrm{Cu}_{3} \mathrm{BiS}_{3}, \mathrm{CBS}\right)$ nanoparticles and rare earth down-conversion (DC) nanoparticles in larger size zeolite imidazole skeleton-8 (ZIF8) nanoparticles and then loaded them with anticancer drugs Doxorubicin (DOX). Under X-ray irradiation, a moderate dose of CBS\&DC-ZIF8@DOX composite material can achieve high (87.6\%) tumor suppression efficiency and synergistic radiotherapy and chemotherapy (119).

\section{Non-Metallic Nanomaterial Sensitizer}

The development of non-metallic nanomaterial sensitizers in the treatment of glioma has also been very rapid, such as selenium (Se) nanoparticles, graphene nanomaterials, etc. (120). Qian Huang et al. synthesized selenium nanoparticles by reducing tin dioxide with vitamin $C$. The selenium nanoparticles were used as sacrificial templates to react with copper ions to form copper selenide nanoparticles. The results showed that the dumbbell-like copper-gold selenide nanocrystals could be used as an effective radiosensitizer for enhanced radiotherapy (121).

In the treatment of gliomas, graphene nanomaterials have also made new progress in the field of sensitization and radiotherapy. Sakine Shirvalilou et al. used magnetic graphene oxide (NGO/SPIONs) nanoparticles (MNPs) coated with PLGA polymers as dynamic nanocarriers for IUDR to achieve 5-iodo-2 deoxyuridine (IUdR) entry into the blood-brain barrier (BBB). IUDR/MNPs were administered intravenously to tumor-bearing rats of the C6 glioma cell line under a magnetic field of 1.3T, and the synergistic effect of IUDR/MNPs and radiotherapy was found. Compared with radiation alone, increasing the ratio of Bax/Bcl-2 (2.13 times) can significantly inhibit tumor expansion $(>100 \%)$ and prolong survival time $(>100 \%)$. Inhibit the antiapoptotic response of glioma rats, thereby enhancing the sensitizing effect of tumor radiotherapy (27). Lei Chen et al. developed ${ }^{131}$ I-labeled, polyethylene glycol (PEG) coated 
reduced graphene oxide (RGO) nanoparticle. After intravenous injection, gamma imaging shows a significant accumulation of ${ }^{131}$ IRGO-PEG in tumor tissue. Reduced graphene oxide has a strong near-infrared absorbance, which can effectively heat tumors under near-infrared irradiation. The ${ }^{131} \mathrm{I}$ emits highenergy X-rays due to ionization, which induces tumor killing and enhances the effect of radiotherapy on cancer cells (122).

\section{Multifunctional Nano-Radiosensitizer}

A simple nanoradiotherapy sensitizer cannot meet the needs of clinical treatment for the characteristics of radiation resistance and immunosuppression of glioma. Functional nanomaterials can improve the radiotherapy sensitivity of gliomas in many ways. Erel-Akbaba $G$ has developed a cyclic peptide iRGD (CCRGDKGPDC)-conjugated solid lipid nanoparticle (SLN) to deliver epidermal growth factor receptor (EGFR) and PD-L1 small interfering RNA (SiRNA), binding to targeted and immunotherapy for glioblastoma and enhancing the efficacy of radiation therapy by regulating the immune system (123). Forrest M. Kievit et al. prepared a nanoparticle (NP) composed of superparamagnetic iron oxide core, biodegradable chitosan, polyethylene glycol (PEG), and polyethyleneimine (PEI) coating. The NP can bind to siRNA and protect it from degradation and deliver siRNA to the area around the target nucleus to use an siRNA vector to inhibit the expression of APE1 and enhance the sensitivity of brain malignancies to RT (124). siRNA itself is a radiotherapy sensitizer. By carrying a certain radiotherapy sensitizer nanocarrier and combining immunotherapy, it can achieve double or even multiple sensitizers, which is also the research focus of future radiotherapy sensitizer nanocarrier.

\section{OUTLOOK}

In summary, the combined application of nanoparticles and radiotherapy sensitizers can significantly improve the effect of radiotherapy. The special biological characteristics of glioma weaken the effect of traditional radiotherapy, and the excellent targeting and good biocompatibility of nano-radiosensitizers solve the difficulties of traditional radiotherapy for glioma. At present, nano-radiosensitizers have developed rapidly in the past few years, providing new research strategies for sensitization of

\section{REFERENCES}

1. Jiang Y, Uhrbom L. On the origin of glioma. Upsala J Med Sci (2012) 117 (2):113-21. doi: 10.3109/03009734.2012.658976

2. Tilleul P, Brignone M, Hassani Y, Labrande C, Pedeboscq S, Gensollen S, et al. A multicenter prospective observational study of the conformity of temozolomide prescriptions in France. Pharmacoepidemiol Drug Saf (2012) 21(8):828-34. doi: 10.1002/pds.3233

3. Chang CN, Huang YC, Yang DM, Kikuta K, Wei KJ, Kubota T, et al. A phase I/II clinical trial investigating the adverse and therapeutic effects of a postoperative autologous dendritic cell tumor vaccine in patients with malignant glioma. J Clin Neurosci Off J Neurosurg Soc Australas (2011) 18 (8):1048-54. doi: 10.1016/j.jocn.2010.11.034 radiotherapy and new ideas for radiotherapy for gliomas. As mentioned earlier, nanoparticles as radiosensitizers have shown great potential in tumor treatment. New drug delivery methods can also improve the sensitizing effect of radiosensitizers (127). Nano-radiosensitizers are characterized by low cytotoxicity, good targeting, good biocompatibility, and easy functionalization. They can pass the blood-brain barrier (BBB), and some of them have been used as radiosensitizers in clinical treatment (128). However, single-functional nanoparticles cannot fully meet clinical needs, and more and more researchers have focused on finding multifunctional nanoparticles that are more conducive to clinical transformation. Furthermore, improving the drug-carrying capacity of nanomaterials is a strategy to develop multifunctional platforms. Research on the radiation sensitization mechanism will provide targets for new radiation sensitizers, and interdisciplinary research will promote the further development of new radiation sensitizers (129).

\section{AUTHOR CONTRIBUTIONS}

HL and YX was responsible for the overall idea of the article. $\mathrm{YH}$ was responsible for the abstract and the fourth part. $\mathrm{XZ}$ was responsible for the Introduction and Outlook and revised the format. HM was responsible for the writing of the second part. LL was responsible for the writing of the third part. All authors contributed to the article and approved the submitted version.

\section{FUNDING}

This work was supported by grants from the National Natural Science Foundation of China [No. 81772665], Social Development Project of Jiangsu Department of Science and Technology [No. BE2020647, BE2020642], Jiangsu provincial Commission of Health and Family Planning [No. Q201608], Six Talents Peak Foundation of Jiangsu Province [No. 2018-WSW071], the Youth Science and Technology Innovation Team of Xuzhou Medical University [No. TD202002], and the Social Development Project of Xuzhou Department of Science and Technology [No. KC20079].
4. Ruiz J, Case D, Enevold G, Rosdhal R, Tatter SB, Ellis TL, et al. A phase II trial of thalidomide and procarbazine in adult patients with recurrent or progressive malignant gliomas. J Neuro Oncol (2012) 106(3):611-7. doi: 10.1007/s11060-011-0698-y

5. Malmström A, Grønberg BH, Marosi C, Stupp R, Frappaz D, Schultz H, et al. Temozolomide versus standard 6-week radiotherapy versus hypofractionated radiotherapy in patients older than 60 years with glioblastoma: the Nordic randomised, phase 3 trial. Lancet Oncol (2012) 13(9):916-26. doi: 10.1016/S1470-2045(12)70265-6

6. Keime-Guibert F, Chinot O, Taillandier L, Cartalat-Carel S, Frenay M, Kantor G, et al. Radiotherapy for glioblastoma in the elderly. New Engl J Med (2007) 356(15):1527-35. doi: 10.1056/NEJMoa065901

7. Nieder C, Astner ST, Mehta MP, Grosu AL, Molls M. Improvement, clinical course, and quality of life after palliative radiotherapy for recurrent 
glioblastoma. Am J Clin Oncol (2008) 31(3):300-5. doi: 10.1097/ COC.0b013e31815e3fdc

8. Karunamuni R, Bartsch H, White NS, Moiseenko V, Carmona R, Marshall DC, et al. Dose-Dependent Cortical Thinning After Partial Brain Irradiation in High-Grade Glioma. Int J Radiat Oncol Biol Phys (2016) 94(2):297-304. doi: 10.1016/j.ijrobp.2015.10.026

9. Shaw E, Arusell R, Scheithauer B, O’Fallon J, O'Neill B, Dinapoli R, et al. Prospective randomized trial of low- versus high-dose radiation therapy in adults with supratentorial low-grade glioma: initial report of a North Central Cancer Treatment Group/Radiation Therapy Oncology Group/Eastern Cooperative Oncology Group study. J Clin Oncol Off J Am Soc Clin Oncol (2002) 20(9):2267-76. doi: 10.1200/JCO.2002.09.126

10. Babaei M, Ganjalikhani M. The potential effectiveness of nanoparticles as radio sensitizers for radiotherapy. BioImpacts BI (2014) 4(1):15-20. doi: 10.5681/bi.2014.003

11. von Essen CF. Radiation enhancement of metastasis: a review. Clin Exp Metastasis (1991) 9(2):77-104. doi: 10.1007/BF01756381

12. Paw I, Carpenter RC, Watabe K, Debinski W, Lo HW. Mechanisms regulating glioma invasion. Cancer Lett (2015) 362(1):1-7. doi: 10.1016/ j.canlet.2015.03.015

13. Kargiotis O, Geka A, Rao JS, Kyritsis AP. Effects of irradiation on tumor cell survival, invasion and angiogenesis. J Neuro Oncol (2010) 100(3):323-38. doi: 10.1007/s11060-010-0199-4

14. Wank M, Schilling D, Schmid TE, Meyer B, Gempt J, Barz M, et al. Human Glioma Migration and Infiltration Properties as a Target for Personalized Radiation Medicine. Cancers (Basel) (2018) 10(11). doi: 10.3390/ cancers 10110456

15. Ostruszka LJ, Shewach DS. The role of cell cycle progression in radiosensitization by 2',2'-difluoro-2'-deoxycytidine. Cancer Res (2000) 60 (21):6080-8.

16. Yang L, Yang X, Tang Y, Zhang D, Zhu L, Wang S, et al. Inhibition of DNA-PK activity sensitizes A549 cells to X-ray irradiation by inducing the ATM-dependent DNA damage response. Mol Med Rep (2018) 17(6):754552. doi: $10.3892 / \mathrm{mmr} .2018 .8828$

17. Jung HS, Rajasekaran N, Song SY, Kim YD, Hong S, Choi HJ, et al. Human Papillomavirus E6/E7-Specific siRNA Potentiates the Effect of Radiotherapy for Cervical Cancer in Vitro and in Vivo. Int J Mol Sci (2015) 16(6):1224360. doi: 10.3390/ijms160612243

18. Ning S, Tian J, Marshall DJ, Knox SJ. Anti-alphav integrin monoclonal antibody intetumumab enhances the efficacy of radiation therapy and reduces metastasis of human cancer xenografts in nude rats. Cancer Res (2010) 70(19):7591-9. doi: 10.1158/0008-5472.CAN-10-1639

19. Adams GE. Chemical radiosensitization of hypoxic cells. Br Med Bull (1973) 29(1):48-53. doi: 10.1093/oxfordjournals.bmb.a070956

20. Fowler JF, Adams GE, Denekamp J. Radiosensitizers of hypoxic cells in solid tumors. Cancer Treat Rev (1976) 3(4):227-56. doi: 10.1016/S0305-7372(76) 80012-6

21. Rezaee M, Hunting DJ, Sanche L. New insights into the mechanism underlying the synergistic action of ionizing radiation with platinum chemotherapeutic drugs: the role of low-energy electrons. Int $J$ Radiat Oncol Biol Phys (2013) 87(4):847-53. doi: 10.1016/j.ijrobp.2013.06.2037

22. de Sousa Cavalcante L, Monteiro G. Gemcitabine: metabolism and molecular mechanisms of action, sensitivity and chemoresistance in pancreatic cancer. Eur J Pharmacol (2014) 741:8-16. doi: 10.1016/ j.ejphar.2014.07.041

23. Tano T, Okamoto M, Kan S, Bando T, Goda H, Nakashiro K, et al. Immunochemoradiotherapy for patients with oral squamous cell carcinoma: augmentation of OK-432-induced helper $\mathrm{T}$ cell 1 response by 5-FU and X-ray irradiation. Neoplasia (New York NY) (2013) 15(7):805-14. doi: $10.1593 /$ neo. 13488

24. Lebwohl D, Canetta R. Clinical development of platinum complexes in cancer therapy: an historical perspective and an update. Eur J Cancer (Oxford Engl 1990) (1998) 34(10):1522-34. doi: 10.1016/S0959-8049(98) 00224-X

25. Xu C, Wang Y, Guo Z, Chen J, Lin L, Wu J, et al. Pulmonary delivery by exploiting doxorubicin and cisplatin co-loaded nanoparticles for metastatic lung cancer therapy. J Controlled Releases Off J Controlled Release Soc (2019) 295:153-63. doi: 10.1016/j.jconrel.2018.12.013
26. Dasari S, Tchounwou PB. Cisplatin in cancer therapy: molecular mechanisms of action. Eur J Pharmacol (2014) 740:364-78. doi: 10.1016/ j.ejphar.2014.07.025

27. Shirvalilou S, Khoei S, Khoee S, Mahdavi SR, Raoufi NJ, Motevalian M, et al. Enhancement radiation-induced apoptosis in C6 glioma tumorbearing rats via $\mathrm{pH}$-responsive magnetic graphene oxide nanocarrier. J Photochem Photobiol B Biol (2020) 205:111827. doi: 10.1016/j.jphotobiol. 2020.111827

28. Tian X, Lara H, Wagner KT, Saripalli S, Hyder SN, Foote M, et al. Improving DNA double-strand repair inhibitor KU55933 therapeutic index in cancer radiotherapy using nanoparticle drug delivery. Nanoscale (2015) 7 (47):20211-9. doi: 10.1039/C5NR05869D

29. Davila E, Klein L, Vogel CL, Johnson R, Ostroy F, Browning S, et al. Phase I trial of misonidazole (NSC\#261037) plus cyclophosphamide in solid tumors. J Clin Oncol Off J Am Soc Clin Oncol (1985) 3(1):121-7. doi: 10.1200/ JCO.1985.3.1.121

30. Masunaga S, Uto $Y$, Nagasawa H, Hori H, Nagata K, Suzuki M, et al. Evaluation of hypoxic cell radio-sensitizers in terms of radio-sensitizing and repair-inhibiting potential. Dependency on p53 status of tumor cells and the effects on intratumor quiescent cells. Anticancer Res (2006) 26(2a):1261-70.

31. Chan P, Milosevic M, Fyles A, Carson J, Pintilie M, Rauth M, et al. A phase III randomized study of misonidazole plus radiation vs. radiation alone for cervix cancer. Radiother Oncol J Eur Soc Ther Radiol Oncol (2004) 70 (3):295-9. doi: 10.1016/j.radonc.2003.11.018

32. Sheehan J, Ionescu A, Pouratian N, Hamilton DK, Schlesinger D, Oskouian RJ, et al. Use of trans sodium crocetinate for sensitizing glioblastoma multiforme to radiation: laboratory investigation. J Neurosurg (2008) 108(5):972-8. doi: $10.3171 / \mathrm{JNS} / 2008 / 108 / 5 / 0972$

33. Sheehan J, Sherman J, Cifarelli C, Jagannathan J, Dassoulas K, Olson C, et al. Effect of trans sodium crocetinate on brain tumor oxygenation. Laboratory investigation. J Neurosurg (2009) 111(2):226-9. doi: 10.3171/2009.3. JNS081339

34. Malouff TD, Peterson JL, Mahajan A, Trifiletti DM. Carbon ion radiotherapy in the treatment of gliomas: a review. J Neuro Oncol (2019) 145(2):191-9. doi: 10.1007/s11060-019-03303-y

35. Rieken S, Habermehl D, Wuerth L, Brons S, Mohr A, Lindel K, et al. Carbon ion irradiation inhibits glioma cell migration through downregulation of integrin expression. Int J Radiat Oncol Biol Phys (2012) 83(1):394-9. doi: 10.1016/j.jijobp.2011.06.2004

36. Kong L, Gao J, Hu J, Lu R, Yang J, Qiu X, et al. Carbon ion radiotherapy boost in the treatment of glioblastoma: a randomized phase I/III clinical trial. Cancer Commun (London England) (2019) 39(1):5. doi: 10.1186/s40880019-0351-2

37. Chan L, Gao P, Zhou W, Mei C, Huang Y, Yu XF, et al. Sequentially Triggered Delivery System of Black Phosphorus Quantum Dots with Surface Charge-Switching Ability for Precise Tumor Radiosensitization. ACS Nano (2018) 12(12):12401-15. doi: 10.1021/acsnano.8b06483

38. Liang C, Chao Y, Yi X, Xu J, Feng L, Zhao Q, et al. Nanoparticle-mediated internal radioisotope therapy to locally increase the tumor vasculature permeability for synergistically improved cancer therapies. Biomaterials (2019) 197:368-79. doi: 10.1016/j.biomaterials.2019.01.033

39. Abbott NJ, Rönnbäck L, Hansson E. Astrocyte-endothelial interactions at the blood-brain barrier. Nat Rev Neurosci (2006) 7(1):41-53. doi: 10.1038/ nrn1824

40. Abbott NJ, Patabendige AA, Dolman DE, Yusof SR, Begley DJ. Structure and function of the blood-brain barrier. Neurobiol Dis (2010) 37(1):13-25. doi: 10.1016/j.nbd.2009.07.030

41. Keaney J, Campbell M. The dynamic blood-brain barrier. FEBS J (2015) 282 (21):4067-79. doi: 10.1111/febs.13412

42. Mergenthaler P, Lindauer U, Dienel GA, Meisel A. Sugar for the brain: the role of glucose in physiological and pathological brain function. Trends Neurosci (2013) 36(10):587-97. doi: 10.1016/j.tins.2013.07.001

43. Kimelberg HK, Nedergaard M. Functions of astrocytes and their potential as therapeutic targets. Neurother J Am Soc Exp Neurother (2010) 7(4):338-53. doi: 10.1016/j.nurt.2010.07.006

44. Obermeier B, Daneman R, Ransohoff RM. Development, maintenance and disruption of the blood-brain barrier. Nat Med (2013) 19(12):1584-96. doi: 10.1038/nm.3407 
45. Liu H, Xie Y, Zhang Y, Cai Y, Li B, Mao H, et al. Development of a hypoxiatriggered and hypoxic radiosensitized liposome as a doxorubicin carrier to promote synergetic chemo-/radio-therapy for glioma. Biomaterials (2017) 121:130-43. doi: 10.1016/j.biomaterials.2017.01.001

46. Zhao X, Ye Y, Ge S, Sun P, Yu P. Cellular and Molecular Targeted Drug Delivery in Central Nervous System Cancers: Advances in Targeting Strategies. Curr Topics Med Chem (2020) 20(30):2762-76. doi: 10.2174/ 1568026620666200826122402

47. Hua L, Wang Z, Zhao L, Mao H, Wang G, Zhang K, et al. Hypoxiaresponsive lipid-poly-(hypoxic radiosensitized polyprodrug) nanoparticles for glioma chemo- and radiotherapy. Theranostics (2018) 8(18):5088-105. doi: $10.7150 /$ thno. 26225

48. Zhang P, Miska J, Lee-Chang C, Rashidi A, Panek WK, An S, et al. Therapeutic targeting of tumor-associated myeloid cells synergizes with radiation therapy for glioblastoma. Proc Natl Acad Sci USA (2019) 116 (47):23714-23. doi: 10.1073/pnas.1906346116

49. Jeremic B, Aguerri AR, Filipovic N. Radiosensitization by gold nanoparticles. Clin Trans Oncol Off Publ Fed Spanish Oncol Soc Natl Cancer Inst Mex (2013) 15(8):593-601. doi: 10.1007/s12094-013-1003-7

50. Hernández-Rivera M, Kumar I, Cho SY, Cheong BY, Pulikkathara MX, Moghaddam SE, et al. High-Performance Hybrid Bismuth-Carbon Nanotube Based Contrast Agent for X-ray CT Imaging. ACS Appl Mat Interfaces (2017) 9(7):5709-16. doi: 10.1021/acsami.6b12768

51. Lusic H, Grinstaff MW. X-ray-computed tomography contrast agents. Chem Rev (2013) 113(3):1641-66. doi: 10.1021/cr200358s

52. McMahon SJ, Paganetti H, Prise KM. Optimising element choice for nanoparticle radiosensitisers. Nanoscale (2016) 8(1):581-9. doi: 10.1039/ C5NR07089A

53. Zang Y, Gong L, Mei L, Gu Z, Wang Q. Bi(2)WO(6) Semiconductor Nanoplates for Tumor Radiosensitization through High- Z Effects and Radiocatalysis. ACS Appl Mat Interfaces (2019) 11(21):18942-52. doi: 10.1021/acsami.9b03636

54. Kobayashi K, Usami N, Porcel E, Lacombe S, Le Sech C. Enhancement of radiation effect by heavy elements. Mutat Res (2010) 704(1-3):123-31. doi: 10.1016/j.mrrev.2010.01.002

55. Liu CJ, Wang CH, Chien CC, Yang TY, Chen ST, Leng WH, et al. Enhanced $\mathrm{X}$-ray irradiation-induced cancer cell damage by gold nanoparticles treated by a new synthesis method of polyethylene glycol modification. Nanotechnology (2008) 19(29):295104. doi: 10.1088/0957-4484/19/29/ 295104

56. Zhang XD, Wu D, Shen X, Chen J, Sun YM, Liu PX, et al. Size-dependent radiosensitization of $\mathrm{PEG}$-coated gold nanoparticles for cancer radiation therapy. Biomaterials (2012) 33(27):6408-19. doi: 10.1016/j.biomaterials.2012.05.047

57. Liu P, Huang Z, Chen Z, Xu R, Wu H, Zang F, et al. Silver nanoparticles: a novel radiation sensitizer for glioma? Nanoscale (2013) 5(23):11829-36. doi: 10.1039/c3nr01351k

58. Cheng Y, Zhu J, Zhao L, Xiong Z, Tang Y, Liu C, et al. (131)I-labeled multifunctional dendrimers modified with BmK CT for targeted SPECT imaging and radiotherapy of gliomas. Nanomed (London England) (2016) 11 (10):1253-66. doi: 10.2217/nnm-2016-0001

59. Kumari A, Yadav SK, Yadav SC. Biodegradable polymeric nanoparticles based drug delivery systems. Colloids Surf B Biointerf (2010) 75(1):1-18. doi: 10.1016/j.colsurfb.2009.09.001

60. Evans SM, Judy KD, Dunphy I, Jenkins WT, Hwang WT, Nelson PT, et al. Hypoxia is important in the biology and aggression of human glial brain tumors. Clin Cancer Res Off J Am Assoc Cancer Res (2004) 10(24):8177-84. doi: 10.1158/1078-0432.CCR-04-1081

61. Siegal T, Charbit H, Paldor I, Zelikovitch B, Canello T, Benis A, et al. Dynamics of circulating hypoxia-mediated miRNAs and tumor response in patients with high-grade glioma treated with bevacizumab. J Neurosurg (2016) 125(4):1008-15. doi: 10.3171/2015.8.JNS15437

62. Song G, Liang C, Yi X, Zhao Q, Cheng L, Yang K, et al. PerfluorocarbonLoaded Hollow Bi2Se3 Nanoparticles for Timely Supply of Oxygen under Near-Infrared Light to Enhance the Radiotherapy of Cancer. Adv Mater (2016) 28(14):2716-23. doi: 10.1002/adma.201504617

63. Zhu D, Lyu M, Jiang W, Suo M, Huang Q, Li K. A biomimetic nanozyme/ camptothecin hybrid system for synergistically enhanced radiotherapy. J Mat Chem B (2020) 8(24):5312-9. doi: 10.1039/D0TB00676A
64. Dutreix M, Cosset JM, Sun JS. Molecular therapy in support to radiotherapy. Mutat Res (2010) 704(1-3):182-9. doi: 10.1016/j.mrrev.2010.01.001

65. Komotar RJ, Otten ML, Moise G, Connolly ES Jr. Radiotherapy plus concomitant and adjuvant temozolomide for glioblastoma-a critical review. Clin Med Oncol (2008) 2:421-2. doi: 10.4137/CMO.S390

66. Radford IR. The level of induced DNA double-strand breakage correlates with cell killing after X-irradiation. Int J Radiat Biol Relat Stud Phys Chem Med (1985) 48(1):45-54. doi: 10.1080/09553008514551051

67. Turnbull T, Douglass M, Williamson NH, Howard D, Bhardwaj R, Lawrence $\mathrm{M}$, et al. Cross-Correlative Single-Cell Analysis Reveals Biological Mechanisms of Nanoparticle Radiosensitization. ACS Nano (2019) 13 (5):5077-90. doi: 10.1021/acsnano.8b07982

68. Yao H, Qiu H, Shao Z, Wang G, Wang J, Yao Y, et al. Nanoparticle formulation of small DNA molecules, Dbait, improves the sensitivity of hormone-independent prostate cancer to radiotherapy. Nanomed Nanotechnol Biol Med (2016) 12(8):2261-71. doi: 10.1016/j.nano.2016. 06.010

69. Liu H, Cai Y, Zhang Y, Xie Y, Qiu H, Hua L, et al. Development of a Hypoxic Radiosensitizer-Prodrug Liposome Delivery DNA Repair Inhibitor Dbait Combination with Radiotherapy for Glioma Therapy. Adv Healthcare Mat (2017) 6(12). doi: 10.1002/adhm.201601377

70. Hamoudeh M, Fessi H, Salim H, Barbos D. Holmium-loaded PLLA nanoparticles for intratumoral radiotherapy via the TMT technique preparation, characterization, and stability evaluation after neutron irradiation. Drug Dev Ind Pharm (2008) 34(8):796-806. doi: 10.1080/ 03639040801918623

71. Song G, Cheng L, Chao Y, Yang K, Liu Z. Emerging Nanotechnology and Advanced Materials for Cancer Radiation Therapy. Adv Mater (2017) 29 (32). doi: 10.1002/adma.201700996

72. Vandergrift WA, Patel SJ, Nicholas JS, Varma AK. Convection-enhanced delivery of immunotoxins and radioisotopes for treatment of malignant gliomas. Neurosurg Focus (2006) 20(4):E13. doi: 10.3171/foc.2006.20.4.8

73. Luther N, Zhou Z, Zanzonico P, Cheung NK, Humm J, Edgar MA, et al. The potential of theragnostic ${ }^{124} \mathrm{I}-8 \mathrm{H} 9$ convection-enhanced delivery in diffuse intrinsic pontine glioma. Neuro Oncol (2014) 16(6):800-6. doi: 10.1093/ neuonc/not 298

74. Allard E, Hindre F, Passirani C, Lemaire L, Lepareur N, Noiret N, et al. 188Re-loaded lipid nanocapsules as a promising radiopharmaceutical carrier for internal radiotherapy of malignant gliomas. Eur J Nucl Med Mol Imaging (2008) 35(10):1838-46. doi: 10.1007/s00259-008-0735-z

75. Vanpouille-Box C, Lacoeuille F, Belloche C, Lepareur N, Lemaire L, LeJeune $\mathrm{JJ}$, et al. Tumor eradication in rat glioma and bypass of immunosuppressive barriers using internal radiation with (188)Re-lipid nanocapsules. Biomaterials (2011) 32(28):6781-90. doi: 10.1016/j.biomaterials.2011.05.067

76. Chaurasiya B, Mahanty A, Roy D, Shen Y, Tu J, Sun C. Influence of Tumor Microenvironment on the Distribution and Elimination of Nanoformulations. Curr Drug Metab (2016) 17(8):783-98. doi: 10.2174/ 1389200217666160607093347

77. Liu J, Yang Y, Zhu W, Yi X, Dong Z, Xu X, et al. Nanoscale metal-organic frameworks for combined photodynamic \& radiation therapy in cancer treatment. Biomaterials (2016) 97:1-9. doi: 10.1016/j.biomaterials.2016.04.034

78. Guan Q, Zhou LL, Li YA, Li WY, Wang S, Song C, et al. Nanoscale Covalent Organic Framework for Combinatorial Antitumor Photodynamic and Photothermal Therapy. ACS Nano (2019) 13(11):13304-16. doi: 10.1021/ acsnano.9b06467

79. Tirapelli LF, Morgueti M, da Cunha Tirapelli DP, Bagnato VS, Ferreira J, Neto FS, et al. Apoptosis in glioma cells treated with PDT. Photomed Laser Surg (2011) 29(5):305-9. doi: 10.1089/pho.2009.2649

80. Lyons M, Phang I, Eljamel S. The effects of PDT in primary malignant brain tumours could be improved by intraoperative radiotherapy. Photodiagnosis Photodynamic Ther (2012) 9(1):40-5. doi: 10.1016/j.pdpdt.2011.12.001

81. Zhuang W, Li B, Long L, Chen L, Huang Q, Liang Z. Induction of autophagy promotes differentiation of glioma-initiating cells and their radiosensitivity. Int J Cancer (2011) 129(11):2720-31. doi: 10.1002/ijc.25975

82. Liu Z, Tan H, Zhang X, Chen F, Zhou Z, Hu X, et al. Enhancement of radiotherapy efficacy by silver nanoparticles in hypoxic glioma cells. Artif Cells Nanomed Biotechnol (2018) 46(sup3):S922-30. doi: 10.1080/21691401. 2018.1518912 
83. Lomonaco SL, Finniss S, Xiang C, Decarvalho A, Umansky F, Kalkanis SN, et al. The induction of autophagy by gamma-radiation contributes to the radioresistance of glioma stem cells. Int J Cancer (2009) 125(3):717-22. doi: $10.1002 /$ ijc. 24402

84. Yuan X, Du J, Hua S, Zhang H, Gu C, Wang J, et al. Suppression of autophagy augments the radiosensitizing effects of STAT3 inhibition on human glioma cells. Exp Cell Res (2015) 330(2):267-76. doi: 10.1016/ j.yexcr.2014.09.006

85. Zhuang W, Qin Z, Liang Z. The role of autophagy in sensitizing malignant glioma cells to radiation therapy. Acta Biochim Et Biophys Sin (2009) 41 (5):341-51. doi: 10.1093/abbs/gmp028

86. Escamilla-Ramirez A, Castillo-Rodriguez RA, Zavala-Vega S, JimenezFarfan D, Anaya-Rubio I, Briseno E, et al. Autophagy as a Potential Therapy for Malignant Glioma. Pharm (Basel) (2020) 13(7). doi: 10.3390/ ph13070156

87. Feng L, Dong Z, Liang C, Chen M, Tao D, Cheng L, et al. Iridium nanocrystals encapsulated liposomes as near-infrared light controllable nanozymes for enhanced cancer radiotherapy. Biomaterials (2018) 181:81-91. doi: 10.1016/j.biomaterials.2018.07.049

88. Lu SL, Liu WW, Cheng JC, Lin LC, Wang CC, Li PC. Enhanced Radiosensitization for Cancer Treatment with Gold Nanoparticles through Sonoporation. Int J Mol Sci (2020) 21(21). doi: 10.3390/ijms21218370

89. Wang X, Zhang C, Du J, Dong X, Jian S, Yan L, et al. Enhanced Generation of Non-Oxygen Dependent Free Radicals by Schottky-type Heterostructures of Au-Bi(2)S(3) Nanoparticles via X-ray-Induced Catalytic Reaction for Radiosensitization. ACS Nano (2019) 13(5):5947-58. doi: 10.1021/ acsnano.9b01818

90. Choi J, Kim G, Cho SB, Im HJ. Radiosensitizing high-Z metal nanoparticles for enhanced radiotherapy of glioblastoma multiforme. J Nanobiotechnol (2020) 18(1):122. doi: 10.1186/s12951-020-00684-5

91. Yang X, Yang M, Pang B, Vara M, Xia Y. Gold Nanomaterials at Work in Biomedicine. Chem Rev (2015) 115(19):10410-88. doi: 10.1021/acs.chemrev. 5 b00193

92. Penninckx S, Heuskin AC, Michiels C, Lucas S. Gold Nanoparticles as a Potent Radiosensitizer: A Transdisciplinary Approach from Physics to Patient. Cancers (Basel) (2020) 12(8). doi: 10.3390/cancers12082021

93. Liu Y, Chen W, Zhang P, Jin X, Liu X, Li P, et al. Dynamically-enhanced retention of gold nanoclusters in HeLa cells following X-rays exposure: A cell cycle phase-dependent targeting approach. Radiother Oncol J Eur Soc Ther Radiol Oncol (2016) 119(3):544-51. doi: 10.1016/j.radonc.2016.04.033

94. Yang YS, Carney RP, Stellacci F, Irvine DJ. Enhancing radiotherapy by lipid nanocapsule-mediated delivery of amphiphilic gold nanoparticles to intracellular membranes. ACS Nano (2014) 8(9):8992-9002. doi: 10.1021/ nn502146r

95. Song G, Chen Y, Liang C, Yi X, Liu J, Sun X, et al. Catalase-Loaded TaOx Nanoshells as Bio-Nanoreactors Combining High-Z Element and Enzyme Delivery for Enhancing Radiotherapy. Adv Mater (2016) 28(33):7143-8. doi: 10.1002/adma.201602111

96. Pagáčová E, Štefančíková L, Schmidt-Kaler F, Hildenbrand G, Vičar T, Depeš D, et al. Challenges and Contradictions of Metal Nano-Particle Applications for Radio-Sensitivity Enhancement in Cancer Therapy. Int J Mol Sci (2019) 20(3). doi: 10.3390/ijms20030588

97. Peng C, Liang Y, Chen Y, Qian X, Luo W, Chen S, et al. Hollow Mesoporous Tantalum Oxide Based Nanospheres for Triple Sensitization of Radiotherapy. ACS Appl Mat Interfaces (2020) 12(5):5520-30. doi: 10.1021/acsami.9b20053

98. Verry C, Dufort S, Lemasson B, Grand S, Pietras J, Troprès I, et al. Targeting brain metastases with ultrasmall theranostic nanoparticles, a first-in-human trial from an MRI perspective. Sci Adv (2020) 6(29):eaay5279. doi: 10.1126/ sciadv.aay5279

99. Chen MH, Hanagata N, Ikoma T, Huang JY, Li KY, Lin CP, et al. Hafniumdoped hydroxyapatite nanoparticles with ionizing radiation for lung cancer treatment. Acta Biomater (2016) 37:165-73. doi: 10.1016/j.actbio.2016.04.004

100. Le Duc G, Roux S, Paruta-Tuarez A, Dufort S, Brauer E, Marais A, et al. Advantages of gadolinium based ultrasmall nanoparticles vs molecular gadolinium chelates for radiotherapy guided by MRI for glioma treatment. Cancer Nanotechnol (2014) 5(1):4. doi: 10.1186/s12645-014-0004-8

101. Briggs A, Corde S, Oktaria S, Brown R, Rosenfeld A, Lerch M, et al. Cerium oxide nanoparticles: influence of the high- $\mathrm{Z}$ component revealed on radioresistant $9 \mathrm{~L}$ cell survival under X-ray irradiation. Nanomed Nanotechnol Biol Med (2013) 9 (7):1098-105. doi: 10.1016/i.nano.2013.02.008

102. Jin J, Zhao Q. Engineering nanoparticles to reprogram radiotherapy and immunotherapy: recent advances and future challenges. J Nanobiotechnol (2020) 18(1):75. doi: 10.1186/s12951-020-00629-y

103. Zhong X, Wang X, Zhan G, Tang Y, Yao Y, Dong Z, et al. $\mathrm{NaCeF(4):Gd,Tb}$ Scintillator as an X-ray Responsive Photosensitizer for Multimodal ImagingGuided Synchronous Radio/Radiodynamic Therapy. Nano Lett (2019) 19 (11):8234-44. doi: 10.1021/acs.nanolett.9b03682

104. Runowski M, Ekner-Grzyb A, Mrówczyńska L, Balabhadra S, Grzyb T, Paczesny J, et al. Synthesis and organic surface modification of luminescent, lanthanide-doped core/shell nanomaterials(LnF3@SiO2@NH2@organic acid) for potential bioapplications: spectroscopic, structural, and in vitro cytotoxicity evaluation. Langmuir ACS J Surf Colloids (2014) 30(31):953343. doi: 10.1021/la501107a

105. Wang J, Wu X, Shen P, Wang J, Shen Y, Shen Y, et al. Applications of Inorganic Nanomaterials in Photothermal Therapy Based on Combinational Cancer Treatment. Int J Nanomed (2020) 15:1903-14. doi: 10.2147/ IJN.S239751

106. Hossain M, Su M. Nanoparticle location and material dependent dose enhancement in X-ray radiation therapy. J Phys Chem C Nanomater Interfaces (2012) 116(43):23047-52. doi: 10.1021/jp306543q

107. Mao F, Wen L, Sun C, Zhang S, Wang G, Zeng J, et al. Ultrasmall Biocompatible $\mathrm{Bi}(2) \mathrm{Se}(3)$ Nanodots for Multimodal Imaging-Guided Synergistic Radiophotothermal Therapy against Cancer. ACS Nano (2016) 10(12):11145-55. doi: 10.1021/acsnano.6b06067

108. Yu H, Yang Y, Jiang T, Zhang X, Zhao Y, Pang G, et al. Effective Radiotherapy in Tumor Assisted by Ganoderma lucidum PolysaccharideConjugated Bismuth Sulfide Nanoparticles through Radiosensitization and Dendritic Cell Activation. ACS Appl Mat Interfaces (2019) 11(31):27536-47. doi: 10.1021/acsami.9b07804

109. Song G, Liang C, Gong H, Li M, Zheng X, Cheng L, et al. Core-Shell MnSe@ Bi2 Se3 Fabricated via a Cation Exchange Method as Novel Nanotheranostics for Multimodal Imaging and Synergistic Thermoradiotherapy. Adv Mater (2015) 27(40):6110-7. doi: 10.1002/adma.201503006

110. Zhang F, Liu S, Zhang N, Kuang Y, Li W, Gai S, et al. X-ray-triggered NOreleased Bi-SNO nanoparticles: all-in-one nano-radiosensitizer with photothermal/gas therapy for enhanced radiotherapy. Nanoscale (2020) 12 (37):19293-307. doi: 10.1039/D0NR04634E

111. Yang C, Mi X, Su H, Yang J, Gu Y, Zhang L, et al. GE11-PDA-Pt@USPIOs nano-formulation for relief of tumor hypoxia and MRI/PAI-guided tumor radio-chemotherapy. Biomater Sci (2019) 7(5):2076-90. doi: 10.1039/ C8BM01492B

112. Fathy MM, Fahmy HM, Saad OA, Elshemey WM. Silica-coated iron oxide nanoparticles as a novel nano-radiosensitizer for electron therapy. Life Sci (2019) 234:116756. doi: 10.1016/j.lfs.2019.116756

113. Fan Y, Zhang J, Shi M, Li D, Lu C, Cao X, et al. Poly(amidoamine) Dendrimer-Coordinated Copper(II) Complexes as a Theranostic Nanoplatform for the Radiotherapy-Enhanced Magnetic Resonance Imaging and Chemotherapy of Tumors and Tumor Metastasis. Nano Lett (2019) 19(2):1216-26. doi: 10.1021/acs.nanolett.8b04757

114. Zhang C, Yan L, Wang X, Dong X, Zhou R, Gu Z, et al. Tumor Microenvironment-Responsive $\mathrm{Cu}(2)(\mathrm{OH}) \mathrm{PO}(4)$ Nanocrystals for Selective and Controllable Radiosentization via the X-ray-Triggered Fenton-like Reaction. Nano Lett (2019) 19(3):1749-57. doi: 10.1021/acs.nanolett.8b04763

115. Meidanchi A, Akhavan O, Khoei S, Shokri AA, Hajikarimi Z, Khansari N. $\mathrm{ZnFe} 2 \mathrm{O} 4$ nanoparticles as radiosensitizers in radiotherapy of human prostate cancer cells. Mat Sci Eng C Mat Biol App (2015) 46:394-9. doi: 10.1016/j.msec.2014.10.062

116. Ma T, Liu Y, Wu Q, Luo L, Cui Y, Wang X, et al. Correction to QuercetinModified Metal-Organic Frameworks for Dual Sensitization of Radiotherapy in Tumor Tissues by Inhibiting the Carbonic Anhydrase IX. ACS Nano (2020) 14(2):2553. doi: 10.1021/acsnano.9b09760

117. Chechetka SA, Yu Y, Zhen X, Pramanik M, Pu K, Miyako E. Light-driven liquid metal nanotransformers for biomedical theranostics. Nat Commun (2017) 8:15432. doi: 10.1038/ncomms15432

118. Dong X, Cheng R, Zhu S, Liu H, Zhou R, Zhang C, et al. A Heterojunction Structured WO(2.9)-WSe(2) Nanoradiosensitizer Increases Local Tumor 
Ablation and Checkpoint Blockade Immunotherapy upon Low Radiation Dose. ACS Nano (2020) 14(5):5400-16. doi: 10.1021/acsnano.9b08962

119. Kang Y, Yu X, Fan X, Aodenggerile, Zhao S, Tu C, et al. Tetramodal Imaging and Synergistic Cancer Radio-Chemotherapy Enabled by Multiple Component-Encapsulated Zeolitic Imidazolate Frameworks. ACS Nano (2020) 14(4):4336-51. doi: 10.1021/acsnano.9b09858

120. Ji DK, Ménard-Moyon C, Bianco A. Physically-triggered nanosystems based on two-dimensional materials for cancer theranostics. Adv Drug Deliv Rev (2019) 138:211-32. doi: 10.1016/j.addr.2018.08.010

121. Huang Q, Zhang S, Zhang H, Han Y, Liu H, Ren F, et al. Boosting the Radiosensitizing and Photothermal Performance of $\mathrm{Cu}(2-\mathrm{x})$ Se Nanocrystals for Synergetic Radiophotothermal Therapy of Orthotopic Breast Cancer. ACS Nano (2019) 13(2):1342-53. doi: 10.1021/acsnano.8b06795

122. Chen L, Zhong X, Yi X, Huang M, Ning P, Liu T, et al. Radionuclide (131)I labeled reduced graphene oxide for nuclear imaging guided combined radioand photothermal therapy of cancer. Biomaterials (2015) 66:21-8. doi: 10.1016/j.biomaterials.2015.06.043

123. Erel-Akbaba G, Carvalho LA, Tian T, Zinter M, Akbaba H, Obeid PJ, et al. Radiation-Induced Targeted Nanoparticle-Based Gene Delivery for Brain Tumor Therapy. ACS Nano (2019) 13(4):4028-40. doi: 10.1021/ acsnano.8b08177

124. Kievit FM, Stephen ZR, Wang K, Dayringer CJ, Sham JG, Ellenbogen RG, et al. Nanoparticle mediated silencing of DNA repair sensitizes pediatric brain tumor cells to $\gamma$-irradiation. Mol Oncol (2015) 9(6):1071-80. doi: 10.1016/j.molonc.2015.01.006

125. Yang Z, Song J, Dai Y, Chen J, Wang F, Lin L, et al. Self-Assembly of Semiconducting-Plasmonic Gold Nanoparticles with Enhanced Optical
Property for Photoacoustic Imaging and Photothermal Therapy. Theranostics (2017) 7(8):2177-85. doi: 10.7150/thno.20545

126. Chen Q, Chen J, Yang Z, Xu J, Xu L, Liang C, et al. Nanoparticle-Enhanced Radiotherapy to Trigger Robust Cancer Immunotherapy. Adv Mater (2019) 31(10):e1802228. doi: 10.1002/adma.201802228

127. Lammertink BHA, Bos C, van der Wurff-Jacobs KM, Storm G, Moonen CT, Deckers R. Increase of intracellular cisplatin levels and radiosensitization by ultrasound in combination with microbubbles. J Controlled Releases Off J Controlled Release Soc (2016) 238:157-65. doi: 10.1016/j.jconrel.2016. 07.049

128. Wang $\mathrm{H}, \mathrm{Mu} \mathrm{X}, \mathrm{He} \mathrm{H}$, Zhang XD. Cancer Radiosensitizers. Trends Pharmacol Sci (2018) 39(1):24-48. doi: 10.1016/j.tips.2017.11.003

129. Dickreuter E, Eke I, Krause M, Borgmann K, van Vugt MA, Cordes N. Targeting of $\beta 1$ integrins impairs DNA repair for radiosensitization of head and neck cancer cells. Oncogene (2016) 35(11):1353-62. doi: 10.1038/ onc.2015.212

Conflict of Interest: The authors declare that the research was conducted in the absence of any commercial or financial relationships that could be construed as a potential conflict of interest.

Copyright $\odot 2021$ Xie, Han, Zhang, Ma, Li, Yu and Liu. This is an open-access article distributed under the terms of the Creative Commons Attribution License (CC BY). The use, distribution or reproduction in other forums is permitted, provided the original author(s) and the copyright owner(s) are credited and that the original publication in this journal is cited, in accordance with accepted academic practice. No use, distribution or reproduction is permitted which does not comply with these terms. 